\title{
Gambiarrádio: um dispositivo livre para transmissão de áudio em educação
}

\author{
Estêvão da Fontoura e Evandro Manara Miletto \\ ${ }^{1}$ Instituto Federal do Rio Grande do Sul - Campus Porto Alegre \\ Av. Cel. Vicente, 281 - Centro - 91.030-041 - Porto Alegre - RS - Brazil \\ estevao.fontoura@farroupilha.ifrs.edu.br, evandro.miletto@poa.ifrs.edu.br
}

\begin{abstract}
Audio transmission in restricted area can bring different possibilities and be explored for education, arts and entertainment purposes. This paper presents an ongoing project that aims to develop an open-based technology device to broadcast audio to portable devices such as smart phones and tablets in a small range called Gambiaradio. The goal of this project is to take advantage of low-cost equipment, based on free software philosophy and make it available to be used in education, providing inclusion of blind students, and live performances, for instance. The main features of the project, the first steps as the next steps of the project.
\end{abstract}

Resumo. A transmissão de áudio em área restrita pode ser explorada para educação, arte e entretenimento, trazendo possibilidades diversas. Este artigo apresenta um projeto em andamento que desenvolve um equipamento de tecnologia livre para transmitir áudio para aparelhos portáteis como smartphones e tablets com uso pontencial para educação, denominado Gambiarrádio. Para atingir tal objetivo, faz uso de tecnologia livre, de baixo custo (Raspberry Pi e Transmissor FM), integradas em um único equipamento, para promover a inclusão de estudantes cegos em turmas com videntes. As principais características do projeto e os primeiros passos são aqui apresentados, assim como as etapas futuras.

\section{Introdução}

Num contexto de crescente conectividade e convergência [Neri 2012], onde smartphones, computadores e tablets são muito presentes no dia a dia de grande parte da população, principalmente entre os jovens, estão dentre os desafios na educação brasileira contemporânea a atração e a manutenção da atenção dos estudantes para os conteúdos disciplinares trabalhados na escola. Neste panorama, as Tecnologias da Informação e Comunicação (TICs) são imprescindíveis e têm sido exploradas no enfrentamento de outro grande desafio: a inclusão das pessoas com deficiência [Meira et al. 2008], [Campoverde and Martini 2011]. Gambiarrádio é o nome provisório do projeto sobre o qual este texto versa, com o objetivo de enfrentar estes dois desafios, ao desenvolver um equipamento capaz de transmitir áudio em ondas de rádio FM utilizando um Raspberry Pi.

Uma das premissas fundamentais do projeto é o desenvolvimento a partir de uma plataforma aberta e livre, visando a criação de uma ferramenta educacional tecnológica 
V Congresso Brasileiro de Informática na Educação (CBIE 2016)

Anais do XXVII Simpósio Brasileiro de Informática na Educação (SBIE 2016)

de baixo custo, revertendo a lógica de altos custos das tecnologias assistivas e retribuindo à sociedade brasileira a oportunidade de realizar estudos de pós-graduação em uma instituição pública, gratuita e de qualidade.

Considerando o alto custo das licenças para uso de software proprietário, é possível inferir que o acesso a esse tipo de programa dificilmente será universal, o que justifica o objetivo de pesquisar e desenvolver alternativas que atendam a necessidade de democratização do acesso a ferramentas livres para a educação, visando a inclusão de pessoas com deficiência e o desenvolvimento de projetos educacionais diversos, inclusive na área das artes.

Este artigo apresenta, portanto, este projeto em andamento intitulado provisoriamente de Gambiarrádio (GR), descrevendo suas principais características, alguns detalhes sobre a arquitetura do equipamento proposto e os próximos passos a serem alcançados para um experimento pleno e teste de avaliação com usuários reais em um contexto real de uso. Na próxima seção, apresenta-se características básicas do projeto seguido da metodologia básica e próximas etapas.

\section{Apresentando a Gambiarrádio}

GR é a junção de diferentes ferramentas para possibilitar a transmissão de som diretamente de um mixador via ondas de rádio FM, sem a passagem por caixas de som ou autofalantes. A ideia inicial foi viabilizar performances musicais e/ou sonoras que fossem audíveis somente para um público específico de ouvintes. Isso foi feito plugando instrumentos elétricos e eletrônicos no mixador e transmitindo seu sinal por um transmissor FM conectado na saída de áudio. A ideia surgiu em 2011 como solução para um trio de músicos amadores que queriam tocar em um apartamento, por prazer, sem se preocuparem se estavam ou não incomodando os vizinhos. Essa proposta, associada à influência da obra de artistas como John Cage, Laurie Anderson, Nam June Paik e David Byrne, só para mencionar alguns, foi o estopim criativo que viabilizou o surgimento da GR.

Em 2007 um evento de performance chamado Musicircus, criado por John Cage, aconteceu durante a $7^{\text {a }}$ Bienal do Mercosul, em Porto Alegre. Realizada pela primeira vez em novembro de 1967 no Stock Pavilion da Universidade de Illinois, a ideia por trás de Musicircus é "nada mais do que um convite a um número de músicos a performarem simultaneamente da forma que eles desejem" [Rønningsgrind 2012]. A intenção de Cage foi criar uma situação em que tanto a criação artística quanto a experiência do público pudessem ser compartilhadas, sem ditar uma estética única. O resultado foi um ambiente de improvisação simultânea tanto de intérpretes quanto de público, em que cada indivíduo presente possuía autonomia dentro de uma composição global de múltiplos estímulos.

\subsection{Arquitetura preliminar}

O atual sistema da GR é baseado na filosofia de software e hardware livres. A versão inicial foi dividida em muitas partes, incluindo mixador e pré-amplificador, equipamentos grandes e pesados que demandaram a utilização de uma mesa de som, ocupando grande espaço, tornando a estação de trabalho da GR algo fixo. A meta agora é alcançar uma estrutura modular e portátil, com um módulo base para fornecer a energia (bateria) e módulos subsequentes anexados por demanda, como minicomputador (RPi) programado para transmitir em FM, mixador, amplificador e equalizador, por exemplo, dependendo 
V Congresso Brasileiro de Informática na Educação (CBIE 2016)

Anais do XXVII Simpósio Brasileiro de Informática na Educação (SBIE 2016)

da funcionalidade desejada para o equipamento naquele dado momento. O RPi possui um processador ARM11 32 bits $700 \mathrm{MHz}, 512 \mathrm{MB}$ de memória RAM, cartão microSD e o Sistema Operacional Linux; bem como, possibilita conexões General Purpose Input/Output (GPIO), portas programáveis de entrada e saída de dados, utilizadas para prover interface entre periféricos [Silva et al. 2015] e é por meio da programação delas que se consegue a transmissão FM. A Figura 1 ilustra uma arquitetura geral do sistema.

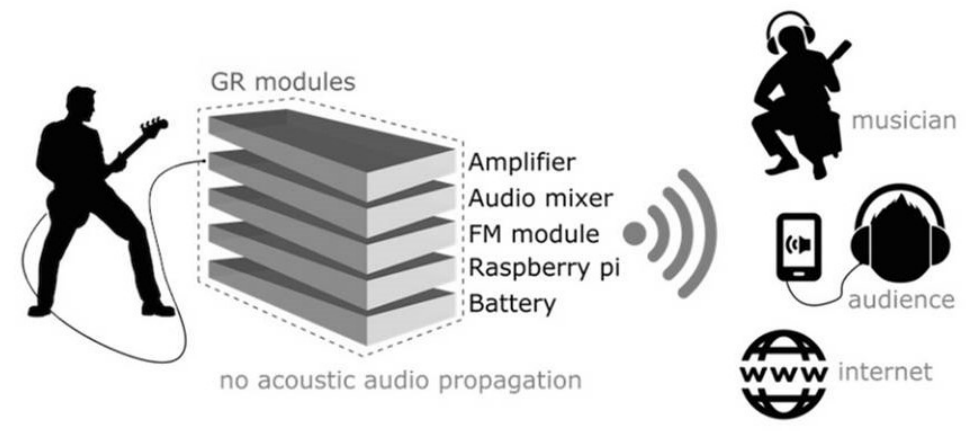

Figura 1. Estrutura modular proposta para o projeto Gambiarrádio

\subsection{Potenciais aplicações da Gambiarrádio}

A versão atual do GR, que está em fase de prototipagem, propiciou o planejamento do protótipo de baixa fidelidade e possibilitou o desenvolvimento de cinco distintas funcionalidades para o dispositivo a serem exploradas, tais como: (a) transmissão temporária e local de rádio FM (para rádios escolares e tradução simultânea), (b) audiodescrição, (c) performances de música experimental e (d) audioguias. Uma descrição mais detalhada é apresentada a seguir.

(a) Transmissão de rádio temporária e local proporciona a criação de uma rádio estudantil, com programação feita por grupos de estudantes ou por turmas e utilização educativa de programas de rádio propostos por professores. É importante a atenção ao fato de que a Lei de Diretrizes e Bases da Educação Nacional (LDBEN) estabelece desde 1996 a música como conteúdo obrigatório do componente curricular Arte, com a alteração feita no texto em 2016, ela passa a ser uma das linguagens obrigatórias do componente curricular Arte [BRASIL ]. Assim, disponibilizar à comunidade escolar um dispositivo capaz de viabilizar a divulgação de pesquisas musicais e de socializar a produção musical feita em projetos na escola torna-se relevante para o contexto educacional. Além disso, seria possível usar o dispositivo para transmissões de comunicação da Direção à toda a comunidade escolar de uma só vez. Ainda, a GR pode ser utilizada neste contexto, convertendo-se também em uma solução de baixo custo, para atividades de tradução simultânea apenas precisando de um professor de línguas capaz de traduzir.

(b) Audiodescrição (AD). Considerando-se a inclusão de Pessoas com Necessidades Educativas Especiais (PNEEs) [Estabel et al. 2006], apoiada pela Lei Federal brasileira (9394/96, Art. 4), todas as escolas do Brasil tem a possibilidade de receber e a obrigatoriedade de acolher estudantes com deficiência, tais como cegos, 
V Congresso Brasileiro de Informática na Educação (CBIE 2016)

Anais do XXVII Simpósio Brasileiro de Informática na Educação (SBIE 2016)

baixa-visão ou surdos, por exemplo. É importante ressaltar que é a escola e a comunidade escolar que devem se adaptar às necessidades específicas da pessoa com deficiência e não o contrário. Nesta situação, GR pode ser utilizada como uma ferramenta promotora da inclusão, permitindo que o professor apresente um vídeo, por exemplo, à sua turma e transmitir via ondas de rádio FM a áudiodescrição correspondente ao vídeo apenas para o estudante cego, que poderia usar um smartphone como receptor.

(c) Plataforma para performances artísticas experimentais que se utilizem das possibilidades abertas pela transmissão FM e via streaming. Para projetos na área da música que, conforme já mencionado, é linguagem obrigatória da disciplina Arte, pode-se explorar o conceito de música ubíqua [Damian Keller 2014]. Desta forma, GR seria uma ferramenta de suporte à criatividade, viabilizando múltiplos usos para a criação de música experimental, como no exemplo da performance mencionada na seção 2 do presente texto.

(d) Áudio Guia (AG): uso estabelecido a partir da transmissão de gravações que mapeiem um determinado espaço, dando conta de descrições sobre um prédio ou área, ou estabelecendo roteiro de visitação à exposições ou espaços, fornecendo explicações e contextualizações em áudio [Bolaños-Mora et al. 2014].

Por sua característica de ser um transmissor de áudio portátil, entre outras coisas, GR tem um grande potencial de promover uma mudança efetiva na forma como os professores e as PNEEs interagem, aumentando o número de atividades que PNEEs pode fazer com os colegas de classe de forma síncrona. Algumas atividades comuns poderiam ser complementadas de forma a socializar a inclusão. Por exemplo, em uma atividade de produção de um vídeo, uma das etapas avaliativas do processo de criação pode ser a produção da $\mathrm{AD}$, o que proporcionaria ao estudante cego participar ativamente, auxiliando numa solução mais adequada, acessível e democrática. Neste processo, todo o grupo estaria operando na Zona de Desenvolvimento Proximal, segundo Vygotsky, [Andrade et al. 2003], tendo um desenvolvimento acima daquele que poderiam ter, caso estivessem trabalhando separadamente [Estabel et al. 2006]. Outros usos podem ser exploradas também nas atividades de ensino de línguas.

\section{Metodologia}

A metodologia inclui pesquisa exploratória numa perspectiva qualitativa envolvendo desenvolvimento de software, fabricação digital, testes e experimentos para validação do produto em contexto real de uso. Para tanto, as seguintes etapas serão desenvolvidas: a) estudo e levantamento bibliográfico identificando o estado da arte (em andamento) basicamente com soluções proprietárias, b) definição de requisitos e necessidades, c) prototipação envolvendo montagem, design e fabricação digital, d) teste e validação no contexto educacional (envolvendo escolas públicas). A análise de dados seguirá uma abordagem mista, sendo majoritariamente qualitativa e parcialmente quantitativa para determinar satisfação de uso através de formulário de teste com usuário [Rubin, J., \& Chisnell 2008].

\section{Perspectivas Futuras}

Este artigo apresentou um trabalho em andamento que visa produzir um dispositivo portátil livre para transmissão de áudio ao vivo, que pode ser usado para diversas atividades no contexto educacional. GR já passou por testes preliminares envolvendo conexões 
V Congresso Brasileiro de Informática na Educação (CBIE 2016)

Anais do XXVII Simpósio Brasileiro de Informática na Educação (SBIE 2016)

de hardware, instalação de software e transmissão simples de áudio, que demonstraram o potencial inicial desta ferramenta. Os próximos passos incluem a finalização do design, implementação dos módulos necessários, fabricação de um case para este dispositivo, bem como a validação do projeto com usuários reais para apresentação de trabalho completo no CBIE 2017. Considerando que serão todos baseados em hardware e software livre, usando uma licença Creative Commons, portanto, um dispositivo livre, GR tem grande potencial para contribuir em vários campos, tornando áudio, música e audiovisual mais acessíveis e realizáveis, principalmente no contexto educacional. Por fim, há a intenção de se produzir o kit GR para colocá-lo disponível para qualquer pessoa interessada em fazer isso, dentro da filosofia Do It Yourself.

\section{Referências}

Andrade, A. F. d., Giraffa, L. M. M., and Vicari, R. M. (2003). Uma aplicação da teoria sociointeracionista de vygotsky para construção de um modelo de aluno. In Anais do XIV Simpósio Brasileiro de Informática na Educação - SBIE 2003, volume 1, pages 525-534.

Bolaños-Mora, A., Cattani, A., and da Costa, F. C. X. (2014). Diretrizes para a inclusão de pessoas cegas em museus. In Anais do XI P\&D Design - Congresso Brasileiro de Pesquisa e Desenvolvimento em Design, volume 1, pages 1-12, Gramado, RS, Brasil. Blucher Design Proceedings.

BRASIL, L. d. D. Bases da educação nacional-ldben-lei 9.394 dezembro de 1996.

Campoverde, P. H. M. and Martini, L. C. (2011). Calculadora financiera finanvox: Herramienta informática educativa de apoyo para deficientes visuales en su proceso de formación académica. In Anais do XXII Simpósio Brasileiro de Informática na Educação - SBIE 2011, volume 1, pages 872-875.

Damian Keller, Victor Lazzarini, M. S. P. (2014). Ubiquitous Music, volume 1. Springer, Springer International Publishing AG, Gewerbestrasse 116330 Cham, Switzerland, 1 edition.

Estabel, L. B., da Silva Moro, E. L., and Santarosa, L. M. C. (2006). A inclusão social e digital de pessoas com limitação visual e o uso das tecnologias de informação e de comunicação na produção de páginas para a internet. Ciência da Informação, 35(1).

Meira, J. N. B., Ferracini, C. C., Gimenes, A. L. M., Neves, F. H. D., and Simonassi, Robsonand Pimentel, E. P. (2008). Uma ferramenta de autoria de materiais instrucionais com símbolos matemáticos acessíveis a deficientes visuais. In Anais do Simpósio Brasileiro de Informática na Educação - SBIE 2008, volume 1, pages 756-765.

Neri, M. C. (2012). Mapa da inclusão digital. Rio de Janeiro: FGV, CPS, page 190.

Rønningsgrind, G. (2012). Meaning, Presence, Process: The Aesthetic Challenge of John Cage's Musicircus. Norges teknisk-naturvitenskapelige universitet, Det humanistiske fakultet, Institutt for musikk.

Rubin, J., \& Chisnell, D. (2008). Handbook of usability testing [electronic resource] : How to plan, design, and conduct effective tests ( 2 nd ed.).

Silva, A. M. E. d., Sá, E., and Teixeira, J. (2015). Especificando objeto de aprendizagem para raspberry pi usando design instrucional. Conferencias LACLO, 6(1):252. 